\title{
Bringing Anomie Back In: Exceptional Events and Excess Suicide
}

\author{
Mark Anthony Hoffman, Peter S. Bearman
}

Columbia University

Abstract: In this article we show that imitation is not the mechanism behind the observed increase in suicides subsequent to highly publicized celebrity suicides. Instead, we show that most celebrity suicides are exceptional events and because of that have similar effects on the daily suicide rate as other exciting events. This finding suggests that Durkheim was right in rejecting the Tardean hypothesis that imitation is an operative mechanism and provides substantial support for the competing hypothesis that disruptive and/or exciting events (whether favorable or unfavorable) induce anomie and with it suicide.

Keywords: imitative suicide; suicide; anomie; Durkheim

Citation: Hoffman, Mark A., and Peter S. Bearman. 2015. "Bringing Anomie Back In: Exceptional Events and Excess Suicide." Sociological Science 2: 186-210.

Received: November 12, 2014 Accepted: November 27, 2014

Published: April 20, 2015

Editor(s): Jesper Sørensen, Gabriel Rossman

D0I: 10.15195/v2.a10

Copyright: (C) 2015 The Author(s). This open-access article has been published under a $\mathrm{Cre}$ ative Commons Attribution License, which allows unrestricted use, distribution and reproduction, in any form, as long as the original author and source have been credited. (c) (i)
L IKE a recurring nightmare, the specter of imitative suicide haunts the imagination of sociologists and the public, returning whenever a celebrity death is reported to be the result of a suicide. The central idea has an old and distinguished provenance, dating back to the fierce debate between Tarde (1969) and Durkheim (1951; 1964) over the social basis of moral life. In most respects, Tarde lost this debate. Aside from a few aficionados (Lepinay and Latour 2009; Latour 2010), Tarde has been consigned to the wastebasket of late nineteenth-century "incoherent thinkers" and Durkheim heralded as a founding father of sociology. Yet strangely, though Tarde lost the theoretical debate (which could have been a mistake), he won the empirical war. The literature on imitation and suicide is almost unanimous in its support of his position. Even if sociologists hold that the general outlines of Durkheim's Suicide are right, they consistently report that excess suicides arise from imitation of the highly publicized suicides of others.

The consensus that suicide is imitative arises from a whole series of empirical studies-all of which purport to establish a meaningful causal relationship between highly publicized suicides and daily or weekly suicide rates. Work in this vein is excellent-overflowing with powerful empirical data, sophisticated regression and time series models, and elegant quasi-experimental designs (Phillips 1974; Bollen and Phillips 1982; Wasserman 1984; Stack 1987). This work leaves little doubt about what the data on suicides report. Across a wide range of places and times, and supported by numerous meta studies and review articles (Gould 2001; Stack 2002), daily counts of suicides increase after a highly publicized suicide. The results are robust. Comparing the days immediately following a publicized suicide to those immediately before, and controlling for all possible confounds, the days after celebrity suicides are associated with excess suicide mortality.

This literature is convincing that days without celebrity suicides in their close past will have a "normal" suicide rate and distribution (by demographic charac- 
teristics such as age, gender, and ethnicity), and that days after celebrity suicides are associated with an excess of suicides. The problem considered in this article is whether this finding has anything to do with imitation or not. To anticipate the main finding-it does not. This is not the case because we find value in the routine-but ultimately entirely unconvincing-objection to the imitation argument that we cannot directly observe imitation. Purveyors of this critique note that if people were to write in their suicide notes that they were imitating a celebrity death suicide we might have some confidence that imitation was the operative mechanism-ignoring the fact that there is often an asymmetry between what people say and what they do (Jerolmack and Khan 2014). But most suicides do not write notes (Timmermans 2005), and there is no record in the literature to suggest that those who do write notes indicate that they are imitating someone else, never mind a celebrity. However, the failure to confirm that a theoretical mechanism operates is hardly a reason to reject the mechanism. We have confidence that the Matthew effect is real not because we observe people saying that they are granting undue credit for shared achievements to higher status individuals but because the empirical patterns arising from status support the idea that they are (Merton 1968; Bearman and Hedstrom 2009). In short, the empirical patterns we observe enable us to impute that the Matthew effect is operating. In the same way, in the literature considered here, imitation as a mechanism is imputed on the basis of observing increased numbers of suicides in the days following a celebrity suicide in contrast to the days preceding such an event. But other explanations are equally consistent with this empirical regularity.

Durkheim's intention in pointing towards anomie was to draw attention to the fact that at certain historical moments asymmetries between integration and normative regulation could lead individuals to be in an anomic condition, and hence subject to increased risk of suicide (Durkheim 1951; Bearman 1991). Anomie arises in this framework because events disrupt stable states:

"[I]f therefore industrial or financial crises increase suicides, this is not because they cause poverty; ... it is because they are ... disturbances of the collective order. Every disturbance of equilibrium, even though it achieves greater comfort and a heightening of general vitality, is an impulse to voluntary death" (Durkheim 1951:246).

Exceptional events that momentarily disrupt the social order are as critical to the anomie argument as are crises. Recall that for Durkheim, "exceptional events" that are scheduled or anticipated because their timing is known in advance will decrease suicidality because they increase social solidarity. We develop-and test-this distinction between disruptive and constructive events subsequently.

It is often observed that what distinguishes sociology from our sister social science disciplines is that we are not content to simply beat the null hypothesis (Abbott 2004). Stronger research designs test real competing hypotheses-that is, they test real competing mechanisms that could be responsible for the patterns that one observes (Abbott 2004). Ironically, the Tardeans of the late twentieth century forgot this fact and were content to argue for the imitation mechanism on the basis of its beating a null hypothesis - that is, by showing that suicides increased after a highly publicized suicide. But note that a Durkheimian would not be surprised that 
highly publicized suicides would lead to an excess of suicide, if such events were disruptive. If suicides increase after events that disrupt the social order, whether these events are positive or negative, then highly publicized suicides would be just another instance of a disruptive event-inducing excess suicide not through imitation, but through anomie. Oddly, this possibility has never been assessed.

Assessing this possibility-that increases in the daily suicide rate follow disruptive events, of which celebrity suicides are but one example-is what we undertake in this article. To anticipate the central finding, suicides increase (as expected) after celebrity suicides. However, suicides increase more when unexpected exciting events happen, and this is true for unambiguously positive events such as news about the first artificial heart transplant in humans, the return to the United States of the hostages held in Iran, and Reagan's famous "Tear down this wall" speech, as well as unambiguously negative events such as the meltdown in Chernobyl, the PLO hijacking of the Achille Lauro, and the sudden death of John Paul I after just 34 days in office. No one doubts that the empirical results of previous work on the effect of celebrity suicides on the daily suicide rate were right. But what the results mean is something else altogether. The fact that exceptional-that is, irregular and disruptive- events of all sorts lead to an increase in suicide tells us, among other indicators, that imitation is not the mechanism at play. The balance of this article is directed towards establishing and extending the points made above with the intention to recognize that it really is the right time to shut the lights off and put the Tardean argument to sleep for good.

\section{Roadmap}

The structure of this article is conventional. We first review the literature related to imitative suicide, focusing on the important extensions of the main effect: for example, evidence for or against homophily in form of suicide and age of victims; on boundary effects (e.g., single-car accidents that could be suicides but are not coded as such); and on the temporal pattern of the effect. This literature is of course nestled in a larger literature on imitation, which suggests wide applicability for imitation as a mechanism shaping behavior as serious as copycat killing (Berkowitz and Macaulay 1971; Phillips and Hensley 1984; Stack 1987) and as trivial as copycat pranks. We distinguish between contexts where an imitation mechanism is reasonable and where it may not be. We then replicate the canonical study that identifies excess suicides. We extend the temporal frame of reference through the last year for which daily suicide data are available in the United States (1988) and discover that the effect remains significant. We observe an exceptional event effect, consistent with Durkheim's discussion of the sources of anomie. Most critically, this effect is stronger for unambiguously positive events than unambiguously negative events. Finally, we extend our observations to consider evidence that might be consistent with imitation over anomie, specifically the idea that imitative suicides ought to imitate something - that is, that the suicides that do occur after a celebrity suicide ought to be homophilous with respect to either method or social demographic characteristics. They are not. We conclude with some reflections on imitation and research design, suggesting that studies that undertake assessment of real compet- 
ing hypotheses are better for advancing knowledge than those that set out just to beat the null.

\section{Previous literature}

Dead for close to a century, the Tardean idea that imitation is an important mechanism to explain suicides and other forms of violence was reincarnated in David Phillips' article, "The Influence of Suggestion on Suicide: Substantive and Theoretical Implications of the Werther Effect" (1974). ${ }^{1}$ In this article, Phillips argued that imitation was operative beyond the micro-level, close-knit networks in which influence was typically seen to operate, and that imitation provided an efficient framework for making sense of "social facts," by which he meant aggregate suicide statistics. Using a quasi-experimental methodology then quite innovative but now common (see, for example, Legewie 2013; Shadish, Cook, and Campbell 2002), Phillips observed what he understood to be evidence for imitation at the macro or national level: an increase in suicides after highly publicized suicides. The basic strategy is to identify an observation window following a publicized suicide as the treatment period, count suicides in that observation window, and contrast (using a t-test) the number of suicides observed to the number of suicides observed in a control period, defined as an observation window of the same length immediately preceding the publicized suicide.

Since the publication of this first paper, a large literature on imitative suicide has confirmed the central finding for the United States, albeit with qualifications here and there (Phillips 1974; Bollen and Phillips 1982; Stack 1987). New articles demonstrate that imitation effects can be observed across a number of countries in North America, Europe, and Asia (Phillips 1974; Jonas 1992; Etzersdorfer 1998; Stack 1996; Huh et al. 2009; Yip et al. 2006) and across multiple time periods and demographic groups (Phillips 1988; Stack 1990). In a series of refinements, other work has shown that the more publicity given to a suicide, the more likely it is that additional suicides will follow (Phillips 1974; Stack 1987; Jonas 1992; Hassan 1995; Gould 2001). Extensions to the effects of real versus fictional suicides (Phillips 1982; Kessler and Stipp 1984; Gould and Schaffer 1986) and observation of the effects of publicized suicides to boundary events that may be suicides but are not coded as such (for example, plane crashes and single-vehicle accidents) (Phillips 1977, 1978, 1979; Bollen and Phillips 1981) are thought to provide further evidence that imitation is operative. Support for the idea that imitation drives excess suicides is also found in extension to other outcome variables where imitation may operate. Thus, the suicide findings are nestled in a larger literature that looks at imitation of highly publicized violence, the effect of heavy weight championship prize fights on homicides (Phillips 1983; Miller et al. 1991), and publicized mass homicides on other mass homicides (Cantor et al. 1999). While this wide body of work tends to use the same quasi-experimental design and paired t-tests, some studies have employed more sophisticated quantitative frameworks (Bollen and Phillips 1982; Wasserman 1984). With respect to imitative suicide, this is one of those cases where the seeming heterogeneity of methods, places, measures, and outcomes all attest 
to the robustness of the finding. About this there is no question: suicides increase after highly publicized suicides.

Of course no literature is without a few wrinkles. If the suicides following a celebrity suicide were imitative one might imagine that there would be homophily with respect to the social demographic characteristics of the celebrities and their followers. This issue has been examined; while some support for the homophily hypothesis is present (Phillips and Carstensen 1986), counterevidence is also observed (Kessler et al. 1988; Baron and Reiss 1985). Likewise, in the original papers and replicated often elsewhere, the imitation effect seems to express unusual temporal patterns, many of which are explained in an ad hoc manner. For example, in the key study replicated in this article, Bollen and Phillips (1982) found that suicides peak on the day of and day after the publication of a highly publicized suicide and then at the end of the week following publication of the story. The observation of such a temporal lag is difficult to make sense of without recourse to ad hoc explanations centered around the need to plan and so on, for which there is no evidence.

These wrinkles aside, the core finding that relative to the period immediately before a celebrity suicide, controlling for obvious temporal confounders, the period after a publicized suicide is associated with greater self-lethality has held up. That this result could have nothing to do with imitation, an obvious point once one remembers the competing Durkheimian anomie theory, has never been subject to a test. The risky test, in this case, is to see if we observe the same effect for another class of events that are disruptive, and whether we observe the same effects for positive as well as negative events. If we do, then disruption, not imitation, is what is driving the observed increase in suicide following highly publicized suicides.

\section{Exceptional events that disrupt the collective order}

Many celebrity suicides are events that can disrupt the collective order. Under both the imitation and anomie mechanisms they ought to be associated with increased suicide. While some celebrity suicides seem straightforward, others are perhaps less so. Likewise, some highly publicized suicides may be disruptive not because of the suicide per se, but because the context in which the suicide occurred challenges established routines and ways of being. In short, the effect of the suicide may be due to imitation or to disruption. In their canonical 1982 paper, Bollen and Phillips describe one of the seven suicides they considered. Here, we quote their description in its entirety:

Christine Chubbuck, a television talk show hostess, shot herself while on the air on Monday, July 15, 1974.

This straightforward description belies a more complex context and some pretty unsettling features that make interpretation of its effect-as imitation or anomiemore difficult. The first thing to note is that Chubbock was a not at all well known. Until she committed suicide she was not really a celebrity. She hosted a 9:00 a.m. talk show on a local television station (Channel 40) in Bradenton/Sarasota, Florida, which was trying to increase ratings by shifting reporting from local news to state and national crime news. At the time of her suicide, the station catchment area 
likely reached fewer than 200,000 people (120,413 people lived in Sarasota County in 1970). What made the event newsworthy-and what made Chubbock a national celebrity-was its sheer horror. But the event was also a deep critique of television news and the motives of those who watched it. Consider the description of events as reported in the Lakeland Ledger, some time after her suicide, here also quoted in its entirety:

Christine Chubbuck flicked her long, dark hair back away from her face, swallowed, twitched her lips only slightly, and reached with her left hand to turn the next page of her script. Looking down on the anchor desk she began to read: "In keeping with Channel 40's policy of bringing you the latest in"-she looked up from the script, directly into the camera and smiled a tentative smile.

Her voice took on a sarcastic tone as she emphasized "blood and guts... and in living color." She looked back down at her script. Her left hand shook almost unnoticeably. Her right arm stiffened. "We bring you another first." Her voice was steady. She looked up again into the camera. Her eyes were dark, direct, and challenging. "An attempted suicide."

Her right hand came up from under the anchor desk. In it was a .38 caliber revolver. She pointed it at the lower back of her head and pulled the trigger. A loud crack was heard. A puff of smoke... from the gun, and her hair flew up around her face as though a sudden gust of wind had caught it. Her face took on a fierce, contorted look, her mouth wrenched downward, her head shook. Then her body fell forward with a resounding thud against the anchor desk and slowly slipped out of sight.

This is not, then, your routine celebrity suicide, if only because Chubbock was not really a celebrity. But it is a deeply disturbing event. Other disturbing events should have, if Durkheim is right, similar consequences for the overall suicide rate. Importantly, though, events that lead to anomie need not be negative disruptions of the collective order; economic boons are as disruptive as declines. Thus to test the anomie hypothesis, we need to identify the population of events-positive or negative - that are disruptive of the collective order, or rather, that could be. The key conceptual idea is that unsettling events upset expectations and induce, in their wake, a structure for anomie.

As noted earlier, anomie-inducing events should be distinguished from exceptional events which are not disruptive: for example, events that are repeated on a fixed or routine schedule, such as sporting events (e.g., the World Series or the Super Bowl), awards ceremonies (e.g., the Oscars, Grammys, Tonys, or Emmys), and domestic political elections; as well as events that, in a sense, have to happen every year, like congressional bills being passed, court decisions being rendered, and people being appointed to hold official office. ${ }^{2}$

Even with this restriction in mind, it is not always obvious what an unsettling event is. With respect to anomie, one way to ascertain if an event was unsettling would be to observe its impact on the suicide rate. ${ }^{3}$ But the goal here is to see 
if anomie is operative-blinding ourselves to the subsequent suicide rate in the selection of events. An immediate problem is that many unsettling events of the past seem trivial today, while events that we may now think were important were of trivial significance when they happened. For example, the founding of Microsoft was meaningless until Microsoft became a powerful corporation years later. Consequently, events of this sort are not included; since they were not salient, they were not publicized. They could hardly lead to anomie.

A more difficult problem is that no days are eventless. Every day some kind of event is publicized: there has to be at least one front-page news story, however trivial it may be. Since every day has an event of some magnitude, it would be impossible to observe excess suicide arising from events, by definition. Consequently, we restrict our attention to significant events occurring during our observation window that were covered by at least two television stations and reported on the front page of the New York Times, and are present in the list of significant events developed by the Info-Please Online Encyclopedia. We select every event that fits these screening criteria, except those events excluded because-as with the original design for celebrity suicides-they border a holiday. ${ }^{4}$

Thus, for example, the December 28, 1981, birth of Elizabeth Carr-the first "test-tube" baby born in the United States-is excluded because it falls just after Christmas and right before the new year. Restriction to events that are listed in the Info-Please Online Encyclopedia rules out events such as Operation Paul Bunyan in August 1976, in which the U.S. Army sent a troop of soldiers to the Korean demilitarized zone to chop down a single tree "as a show of force" in response to the killing of two U.S. officers three days prior. The fear, at the time, was that this could start a cascade on the Korean Peninsula, rekindling the Korean War. It didn't happen. The North Koreans backed off. The show of force worked!

The strategy we use to restrict our focus to unsettling events that contemporaries found salient, were heavily publicized, and did not border holidays, has the added benefit of enabling exact replication of Bollen and Phillips' (1982) imitative suicide study.

\section{Data and Methods}

We replicate Bollen and Phillips' (1982) canonical study and compare the replication to an analysis of highly publicized events using their exact methodology. To ensure comparability between studies, we first (re-)collect Bollen and Phillips' data, using daily suicide statistics from the National Center for Health Statistics and information on the television broadcast coverage of suicides using the Vanderbilt TV News database for the period 1973-1988. ${ }^{5}$ We select the set of highly publicized suicides included in their study; also add disruptive events from the same period (19731976); and then for the full period for which suicide data are available at daily resolution (1973-1988). For this 16-year period, we include 94 events, ranging from the final withdrawal of U.S. soldiers from Vietnam to the Challenger tragedy, giving us a broad understanding of the effect of unsettling events on suicide. The events and suicides that make the screen for inclusion in this study are listed in the 
Table 1: Replication of Bollen and Phillips (1982) for the period 1973-1976

\begin{tabular}{lccc}
\hline $\begin{array}{l}\text { Date of } \\
\text { Publicized } \\
\text { Event }\end{array}$ & $\begin{array}{c}\text { Suicides in } \\
\text { Experimental } \\
\text { Period }\end{array}$ & $\begin{array}{c}\text { Suicides in } \\
\text { Control } \\
\text { Period }\end{array}$ & $\begin{array}{c}\text { Difference between } \\
\text { Experimental and } \\
\text { Control Period Suicides }\end{array}$ \\
\hline June 4, 1973 & 528 & 489 & 93 \\
September 11, 1973 & 487 & 514 & -27 \\
July 15, 1974 & 482 & 462 & 20 \\
April 11, 1975 & 593 & 572 & 21 \\
September 3, 1975 & 553 & 530 & 52 \\
May 13, 1976 & 550 & 575 & -25 \\
\hline
\end{tabular}

appendix, along with the counts of excess (or decreased) suicides associated with each event.

The classic strategy for isolating what appears to be an imitation effect, used in the original study and replicated across the literature, has been to exploit a quasiexperimental design (Shadish, Cook, and Campbell 2002) that compares the suicide count in the week prior to the publication of a suicide story (or event story) to that of the week following. This approach has been complemented by time series analyses to control for potentially confounding temporal factors. Throughout this article, we follow this design and report findings from both the simple quasi-experimental framework and the more sophisticated time series approach. Throughout, we consider the same period Bollen and Phillips investigated, the full period for which data are available, and the effect of positive events on the subsequent suicide rate.

One obvious expectation, if imitation is believed to be operative, is that those influenced by a highly publicized suicide should disproportionately use the same method used in the publicized story. Likewise, we would anticipate that those thought to mimic the original suicide would-with respect to social demographic characteristics - be similar to the person they are presumed to be imitating. We test both of these ideas. Finally, we run robustness checks to ensure that our results are not a spurious result of event choice.

\section{Quasi-Experimental Results}

Following Bollen and Phillips, we first employ a simple quasi-experimental design, replicating their design decisions. We define the control window as the week prior to the event, unless that week contains a holiday or another event. Again following Bollen and Phillips, if a holiday precedes the event too closely, we move the control period back one additional week. This holds the seasonal and day-ofweek variation constant while correcting for holiday and event effects on the control period. The experimental or treatment period always includes the day of the event and the six days that follow. In our initial analysis, we subtract the suicide count in the control period from that of the experimental period. One observes an effect of highly publicized events on suicide counts-which we will refer to as excess suicides-when more suicides occur in the treatment window. 

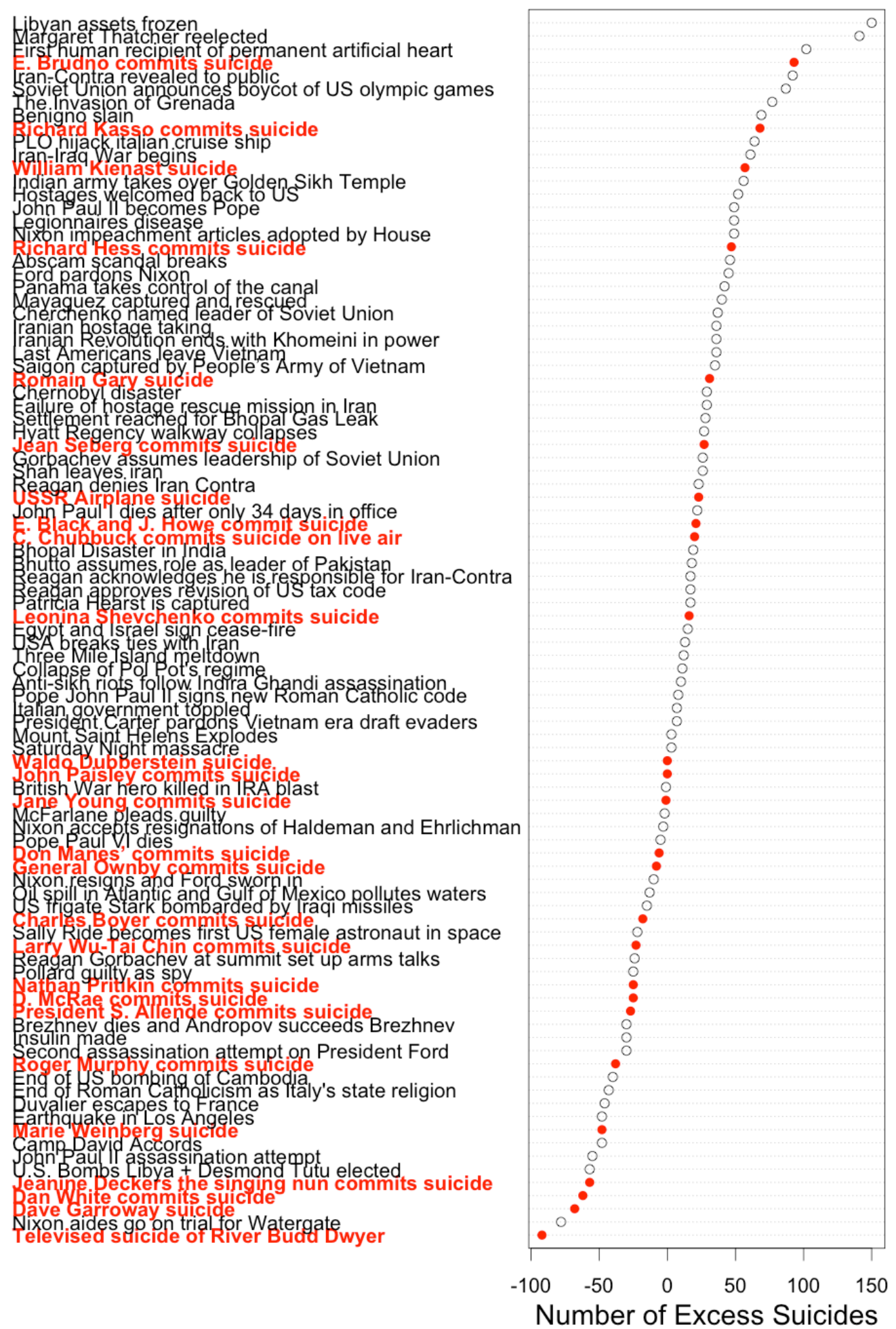

Figure 1: Excess suicides arising from exceptional events and celebrity suicides, 1973-1988 

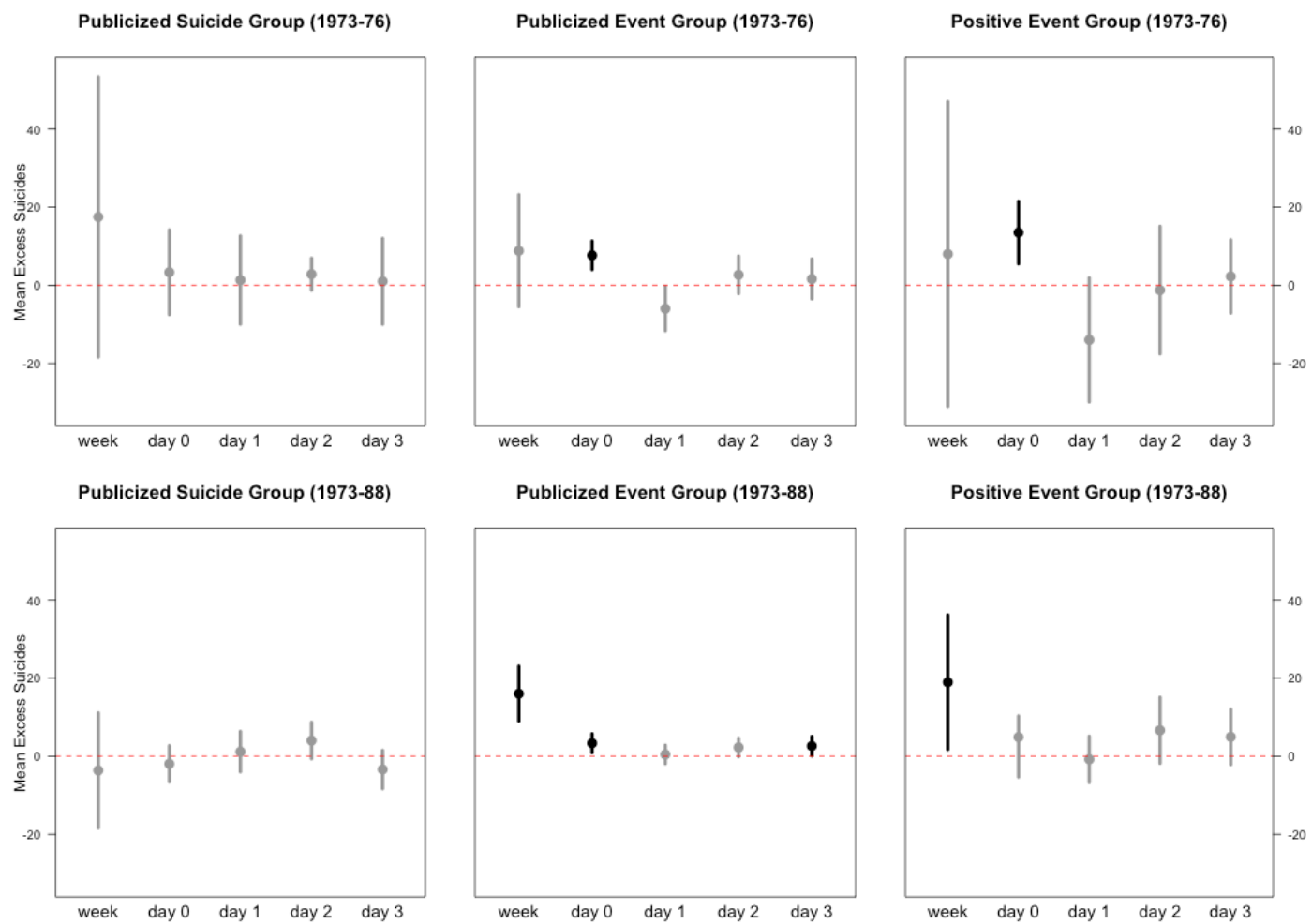

Figure 2: The effects of celebrity suicide and exceptional events in a quasi-experimental context

Table 1 shows our replication of the quasi-experimental results from Bollen and Phillips' original paper for both the 1973-1976 and the 1973-1988 periods. As noted earlier, for the 1972-1976 period we are able to exactly replicate their results. However, restricting our focus to 1973-1976 (thereby eliminating the potential double-counting in their 1972 data; see note 5) changes the picture. Neither celebrity suicides nor events in this window are significantly associated with excess suicide. We compare these results to Figure 1, which shows a dot plot of excess suicides for both highly publicized suicides and events. Publicized suicides and disruptive events are on the y-axis, with events and suicides ordered with respect to the number of subsequent suicides. Highly publicized suicides are red-filled circles in bold font. Significant events (to improve readability we select a random sample of 67 events; see the appendix for the full event list) are indicated by empty circles. The $\mathrm{x}$-axis reports the number of excess suicides; suicide counts are bolded. One can immediately see that the highly publicized suicides are relatively evenly distributed within the event group and that the average excess of suicides for both groups far exceeds zero. Still, some events and some highly publicized suicides do not always lead to excess suicides; this could be a result of confounding temporal effects, which we will address with the time series analysis.

We used a paired t-test to analyze whether the effects of highly publicized suicides and events are statistically significant. Figure 2 compares excess suicides 
for the week following and each of the three days immediately following highly publicized events and highly publicized suicides, along with confidence intervals for the 1973-1976 and 1973-1988 periods. For the week as a whole, highly publicized events led to, on average, 8.83 excess suicides, which is insignificant at the 0.05 level $(\mathrm{t}=1.07, \mathrm{df}=17)$, while highly publicized suicides on average led to 17.5 excess suicides, also insignificant at the 0.05 level $(t=0.98, \mathrm{df}=5) .{ }^{6}$ These results indicate that though many highly publicized, disruptive events (and celebrity suicides) from 1973-1976 led to excess suicide, many did not. For those that do, using the logic implicit in the imitative suicide literature we would have to interpret the excess suicides following Agnew's resignation and the July 1976 outbreak of Legionnaires disease as caused by imitation. That makes no sense. The mechanism by which these events drive excess suicide has to be something other than imitation.

The picture changes dramatically when we extend our analysis to the full period. Here we obtain significant results-and the excess suicide means are lower for the suicide group and greater for the event group. For the full period, highly publicized events led to an average of 15.33 excess suicides, which is significant at the 0.05 level $(\mathrm{t}=3.57, \mathrm{df}=92)$, while highly publicized suicides led to -3.65 excess suicides $(t=-0.42, d f=25){ }^{7}$. These results are visualized at the bottom of Figure 2 . It is easy, then, to falsify the imitation argument. If one did not have a legitimate competing theory, all one could say from these data is that salient, highly publicized important events - of which celebrity suicides are a component-lead to an increase in suicide. Since we have a legitimate theory-anomie-that competes with the imitation idea, we can say that the findings are consistent with that theory, in contrast to the Tarde-inspired imitation hypothesis.

\section{Time Series Analysis}

In order to control for confounding temporal effects, we conduct a time series analysis. We run four separate regressions: one using only highly publicized suicides and one using only highly publicized events, for both the 1973-1976 period and the full period. We include all of the same dummy variables as is standard in the literature as our controls: for each day of the week, excluding Sunday; for each month, excluding December; for each year, excluding the last year in each period; and for holidays. There are strong seasonal and weekly effects that influence suicide counts. For example, holidays suppress suicides. These effects are not described in this article, but a review can be found in the literature (Phillips and Wills 1987; Lester and Beck 1975). The dependent variable of interest is the suicide count for each day of the week following a suicide (or event).

Table 2 reports the suicide outcomes arising from celebrity suicides for the period from 1973-1976, thereby replicating Bollen and Phillips' analysis. In their analyses Bollen and Phillips control for the suicide count from the previous day, here denoted as lagged suicides. The day of the celebrity suicide is indexed as "Day (0)," and the subsequent days follow as "Day (1), Day (2)," etc. Here we can see that a celebrity suicide on Day (0) led to a conditional average of 7.45 excess suicides on Day (1). As with the original paper, we see a strange (though not significant) bump on day (6) as well. Table 2 also reports the suicide outcomes arising from the 
Table 2: The effect of celebrity suicide and exceptional events on daily suicide, 1973-1976

\begin{tabular}{|c|c|c|c|}
\hline \multirow{2}{*}{$\begin{array}{l}\text { Suicides 1973-76 } \\
\text { Intercept }\end{array}$} & \multirow{2}{*}{$\begin{array}{c}\text { Coefficient } \\
61.89 \\
(2.07)\end{array}$} & \multicolumn{2}{|c|}{ 95\% Conf. Int. } \\
\hline & & 57.83 & 65.95 \\
\hline Lagged suicides & $\begin{array}{c}0.09 \\
(0.03)\end{array}$ & 0.04 & 0.14 \\
\hline $\operatorname{Day}(0)$ & $\begin{array}{c}4.44 \\
(3.82)\end{array}$ & -3.05 & 11.94 \\
\hline $\operatorname{Day}(1)$ & $\begin{array}{r}7.45^{\dagger} \\
(3.82)\end{array}$ & -0.05 & 14.94 \\
\hline $\operatorname{Day}(2)$ & $\begin{array}{c}2.13 \\
(3.83)\end{array}$ & -5.37 & 9.64 \\
\hline $\operatorname{Day}(3)$ & $\begin{array}{c}-1.48 \\
(3.82)\end{array}$ & -8.97 & 6.02 \\
\hline $\operatorname{Day}(4)$ & $\begin{array}{c}0.72 \\
(3.82)\end{array}$ & -6.78 & 8.21 \\
\hline $\operatorname{Day}(5)$ & $\begin{array}{c}0.74 \\
(3.82)\end{array}$ & -6.75 & 8.24 \\
\hline $\operatorname{Day}(6)$ & $\begin{array}{c}4.85 \\
(3.82)\end{array}$ & -2.64 & 12.34 \\
\hline Events 1973-76 & Coefficient & $95 \%$ & af. Int. \\
\hline Intercept & $\begin{array}{l}61.89 \\
(2.07)\end{array}$ & 57.83 & 65.95 \\
\hline Lagged suicides & $\begin{array}{c}0.10 \\
(0.07)\end{array}$ & -0.40 & 0.14 \\
\hline $\operatorname{Day}(0)$ & $\begin{array}{c}5.41^{*} \\
(2.21)\end{array}$ & 1.07 & 9.75 \\
\hline $\operatorname{Day}(1)$ & $\begin{array}{c}2.22 \\
(2.22)\end{array}$ & -2.13 & 6.58 \\
\hline $\operatorname{Day}(2)$ & $\begin{array}{c}1.70 \\
(2.22)\end{array}$ & -2.65 & 6.06 \\
\hline $\operatorname{Day}(3)$ & $\begin{array}{c}2.12 \\
(2.22)\end{array}$ & -2.23 & 6.48 \\
\hline $\operatorname{Day}(4)$ & $\begin{array}{c}0.04 \\
(2.22)\end{array}$ & -4.31 & 4.40 \\
\hline $\operatorname{Day}(5)$ & $\begin{array}{c}2.80 \\
(2.22)\end{array}$ & -1.56 & 7.16 \\
\hline $\operatorname{Day}(6)$ & $\begin{array}{c}0.26 \\
(2.22)\end{array}$ & -4.10 & 4.62 \\
\hline
\end{tabular}

* Significant at a 0.05 level, + Significant at a 0.1 level. 
Table 3: The effect of celebrity suicide and exceptional events on daily suicide, 1973-1988

\begin{tabular}{|c|c|c|c|}
\hline \multirow{2}{*}{$\begin{array}{l}\text { Suicides 1973-76 } \\
\text { Intercept }\end{array}$} & \multirow{2}{*}{$\begin{array}{c}\text { Coefficient } \\
68.10 \\
(1.21)\end{array}$} & \multicolumn{2}{|c|}{$95 \%$ Conf. Int } \\
\hline & & 65.73 & 70.46 \\
\hline Lagged suicides & $\begin{array}{c}0.10 \\
(0.01)\end{array}$ & 0.07 & 0.12 \\
\hline $\operatorname{Day}(0)$ & $\begin{array}{c}0.86 \\
(1.93)\end{array}$ & -2.93 & 4.64 \\
\hline $\operatorname{Day}(1)$ & $\begin{array}{r}4.13^{*} \\
(1.93)\end{array}$ & 0.35 & 7.92 \\
\hline $\operatorname{Day}(2)$ & $\begin{array}{r}3.36^{+} \\
(1.93)\end{array}$ & -0.43 & 7.15 \\
\hline $\operatorname{Day}(3)$ & $\begin{array}{c}-2.26 \\
(1.93)\end{array}$ & -6.05 & 1.52 \\
\hline $\operatorname{Day}(4)$ & $\begin{array}{c}-1.11 \\
(1.93)\end{array}$ & -4.89 & 2.68 \\
\hline $\operatorname{Day}(5)$ & $\begin{array}{c}1.65 \\
(1.93)\end{array}$ & -2.13 & 5.44 \\
\hline $\operatorname{Day}(6)$ & $\begin{array}{c}-0.23 \\
(1.93)\end{array}$ & -4.02 & 3.55 \\
\hline Events 1973-88 & Coefficient & \multicolumn{2}{|c|}{ 95\% Conf. Int } \\
\hline Intercept & $\begin{array}{l}68.08 \\
(1.21)\end{array}$ & 65.71 & 70.44 \\
\hline Lagged suicides & $\begin{array}{c}0.10 \\
(0.01)\end{array}$ & 0.07 & 0.12 \\
\hline $\operatorname{Day}(0)$ & $\begin{array}{c}2.2^{*} \\
(1.03)\end{array}$ & 0.18 & 4.22 \\
\hline $\operatorname{Day}(1)$ & $\begin{array}{r}2.65^{*} \\
(1.03)\end{array}$ & 0.64 & 4.67 \\
\hline $\operatorname{Day}(2)$ & $\begin{array}{c}1.11 \\
(1.03)\end{array}$ & -0.90 & 3.13 \\
\hline $\operatorname{Day}(3)$ & $\begin{array}{r}1.87^{\dagger} \\
(1.03)\end{array}$ & -0.16 & 3.87 \\
\hline $\operatorname{Day}(4)$ & $\begin{array}{c}0.15 \\
(1.03)\end{array}$ & -1.86 & 2.17 \\
\hline $\operatorname{Day}(5)$ & $\begin{array}{c}0.58 \\
(1.03)\end{array}$ & -1.44 & 2.60 \\
\hline $\operatorname{Day}(6)$ & $\begin{array}{c}0.41 \\
(1.03)\end{array}$ & -1.61 & 2.42 \\
\hline
\end{tabular}

* Significant at a 0.05 level, + Significant at a 0.1 level. 
Table 4: The effect of positive exceptional events on daily suicide, 1973-1988

\begin{tabular}{lccc}
\hline Positive Events 1973-88 & Coefficient & \multicolumn{2}{c}{$95 \%$ Conf. Int. } \\
\hline Intercept & 68.15 & 65.78 & 70.51 \\
& $(1.21)$ & & \\
Lagged suicides & 0.10 & 0.07 & 0.12 \\
& $(0.01)$ & & \\
Day(0) & 3.84 & -0.98 & 8.66 \\
Day(1) & $(2.46)$ & & \\
& $4.79^{\dagger}$ & -0.03 & 9.61 \\
Day(2) & $(2.46)$ & & \\
& $5.3^{*}$ & 0.48 & 10.12 \\
Day(3) & $(2.46)$ & & \\
& $4.95^{*}$ & 0.13 & 9.77 \\
Day(4) & $(2.46)$ & & \\
& 0.29 & -4.53 & 5.11 \\
Day(5) & $(2.46)$ & & \\
& 0.51 & -4.31 & 5.33 \\
Day(6) & $(2.46)$ & & \\
& -2.20 & -7.05 & 2.59 \\
\hline
\end{tabular}

* Significant at a 0.05 level, + Significant at a 0.1 level.

significant events for the period from 1973 to 1976. The pattern is roughly the same, although events have a slightly attenuated effect.

Table 3 reports suicide outcomes for suicides and events, extending the temporal frame to the period from 1973 through 1988. As expected, the two days immediately following a celebrity suicide are associated with excess suicide. Turning to events, we observe the same general pattern: the day of the event, the day immediately after, and the third day are associated with significantly more suicide. Thinking about the significant results for the week as a whole, one can observe that the effect of celebrity suicides is comparable to the effect of events with respect to excess suicide. Summing all of the coefficients shows that an average of 6.4 excess suicides occurred in the day of and days immediately following a celebrity suicide. The same operation yields 8.9 excess suicides for events.

A key idea in Durkheim's treatment of suicide is that the events that precipitate anomie need not be negative. We consider whether we can find support for the anomie hypothesis by focusing on the effects of positive events on excess suicide. To do this, we replicate the time series analysis considering only unambiguously positive events. The results from this study are reported in Table 4 .

Here we observe that Days (1-3) following a positive event are significantly associated with excess suicide. The effect is much stronger than that observed for all events and for celebrity suicides. Summing all of the coefficients shows that an average of 17.5 excess suicides occurred in the day of and days immediately following a positive event. This temporal pattern for positive events-which are 
Table 5: Homophily by Mode of Suicide

Mean Proportion of People who Used Each Method

Method used in

\begin{tabular}{lcrrrrrr} 
highly publicized suicide & Firearm & Poisoning & Asphyx. & Submers. & Cutting & Jumping & Other \\
\hline Firearm $(n=9)$ & $55.58 \%$ & $21.95 \%$ & $14.39 \%$ & $2.34 \%$ & $1.23 \%$ & $2.77 \%$ & $1.74 \%$ \\
Poisoning $(n=6)$ & $56.27 \%$ & $20.35 \%$ & $15.17 \%$ & $2.33 \%$ & $1.39 \%$ & $2.46 \%$ & $2.04 \%$ \\
Asphyxiation $(n=5)$ & $60.00 \%$ & $18.29 \%$ & $14.52 \%$ & $1.74 \%$ & $1.46 \%$ & $2.82 \%$ & $1.17 \%$ \\
Submersion $(n=1)$ & $57.28 \%$ & $23.03 \%$ & $11.22 \%$ & $1.97 \%$ & $1.77 \%$ & $2.56 \%$ & $2.17 \%$ \\
Cutting $(n=2)$ & $58.96 \%$ & $19.31 \%$ & $13.87 \%$ & $1.72 \%$ & $2.09 \%$ & $2.16 \%$ & $1.89 \%$ \\
Jumping $(n=1)$ & $55.99 \%$ & $23.61 \%$ & $14.33 \%$ & $1.69 \%$ & $0.84 \%$ & $1.69 \%$ & $1.85 \%$ \\
Unknown $(n=2)$ & $54.18 \%$ & $21.43 \%$ & $15.96 \%$ & $2.07 \%$ & $1.53 \%$ & $2.66 \%$ & $2.17 \%$ \\
Baseline & $57.4 \%$ & $21.0 \%$ & $13.9 \%$ & $1.8 \%$ & $1.5 \%$ & $2.7 \%$ & $1.7 \%$ \\
\hline
\end{tabular}

not associated with increased suicide on the day of the event, but are on the day immediately following-may suggest that the immediate effect of such events induces solidarity, with anomie only arriving subsequently, in the wake of the new opportunities such events appear to bring with them. As Durkheim suggests, "So long as the social forces thus freed have not regained equilibrium, their respective values are unknown and so all regulation is lacking for a time ... Consequently there is no restraint upon aspirations" (Durkheim 1951:253).

\section{Testing for homophily: Suicide modality and social demo- graphic characteristics}

It makes sense that if imitation is an operative mechanism, those who imitate a celebrity suicide might select the same method used by the celebrity. We consider this possibility. Table 5 reports the results of this analysis.

The bottom row of Table 5 reports the baseline rate for suicide for each modality. Thus, using a firearm accounts for 57.4 percent, poisoning accounts for 21 percent, and so on, of all suicides reported in the period from 1973-1988 in what we identify as the "no-occurrence" period-that is, those moments not in the temporal window of a celebrity suicide or an event. Reading down the columns, where each row is associated with a mode of celebrity suicide, one can quickly observe that there is no deviation from the baseline rate. If people are imitating celebrities, they are doing it in their own way. There is absolutely no evidence for imitation here. At this point, we should not be surprised, since the evidence for imitation as a mechanism-once we observe that events, and especially positive events, have the same impact on the daily suicide count-is largely absent.

Still, it is possible that influence does not extend to mode of suicide, but that individuals who are similar to the celebrities who committed suicide are more influenced by the suicide than those who are less similar. We consider this possibility in Table 6, which reports homophily by gender and race/ethnicity. ${ }^{8}$ 
Table 6: Homophily by Social Demographic Characteristics

\begin{tabular}{|c|c|c|c|}
\hline \multirow[b]{2}{*}{ Sex of person(s) in publicized suicide } & \multicolumn{3}{|c|}{$\begin{array}{c}\text { Mean Proportion } \\
\text { in Experimental Period }\end{array}$} \\
\hline & Male & Female & \\
\hline Male & $76.29 \%$ & $23.71 \%$ & \\
\hline Female & $75.46 \%$ & $24.54 \%$ & \\
\hline Baseline & $75.7 \%$ & $24.3 \%$ & \\
\hline Race of person(s) in publicized suicide & White & Black & Other \\
\hline White $(n=23)$ & $92.64 \%$ & $6.00 \%$ & $1.35 \%$ \\
\hline Non-White $(n=2)$ & $94.53 \%$ & $3.46 \%$ & $2.01 \%$ \\
\hline Unknown $(n=1)$ & $91.9 \%$ & $6.20 \%$ & $1.9 \%$ \\
\hline Baseline & $92.3 \%$ & $6.00 \%$ & $1.70 \%$ \\
\hline
\end{tabular}

As with Table 5, the bottom row of Table 6 reports the baseline rate for suicide for each category. One can immediately observe that there is almost no deviation from the baseline rate. Some odd results obtain, for example the observation that non-white celebrity suicides are associated with more white suicides, a sort of reverse homophily. But the differences here and elsewhere in these tables are not significant and are probably just statistical noise.

\section{Repeated exciting events on schedules}

Earlier we observed that Durkheim argues for a conceptual distinction between the exceptional disruptive events we have considered so far and repeated constructive events that are more likely to induce solidarity than anomie. We can directly assess this idea with two aims in mind. First, such a test can serve a robustness function. One of the implications of our argument is that constructive events should not be associated with excess suicide, and so observing whether this is the case or not provides another arena for a risky test of our hypothesis. Second, such a test contributes to a theory of events by clarifying the dimensions around which events ought to be grouped into equivalency classes.

Using the quasi-experimental strategy described previously, we confirm that exceptional but expected events (i.e., constructive events) are not associated with excess suicide. The t-test for comparison of the control and treatment conditions is not significant. For the full 1973-1988 period, we consider the effects of presidential and congressional elections, the Super Bowl, and awards ceremonies, including only repeated events that do not overlap with highly publicized suicides and other exceptional events. The Super Bowl had an insignificant, positive effect on excess suicides (mean $=10.3, \mathrm{df}=15, \mathrm{p}=0.36)$, as did elections (mean $=3.847, \mathrm{df}=$ $6, \mathrm{p}=0.80$ ). Major awards ceremonies (mean $=-6.42, \mathrm{df}=44, \mathrm{p}=0.27$ ) are also associated with decreases in daily suicide. As with holidays, which also occur at 
Table 7: The attenuating effect of repeated (constructive) events on suicide mortality

\begin{tabular}{lccc}
\hline Repeated Events 1973-88 & Coefficient & \multicolumn{2}{c}{$95 \%$ Conf. Int. } \\
\hline Intercept & 67.99 & 65.62 & 70.35 \\
& $(1.21)$ & & \\
Lagged suicides & 0.10 & 0.08 & 0.13 \\
Day(0) & $(0.01)$ & & \\
& 0.94 & -1.29 & 3.16 \\
Day(1) & $(1.13)$ & & \\
& 0.23 & -2.00 & 2.46 \\
Day(2) & $(1.14)$ & & 2.70 \\
Day(3) & 0.47 & -1.76 & \\
& $(1.14)$ & & \\
Day(4) & 1.30 & -0.91 & 3.55 \\
Day(5) & $(1.14)$ & & \\
& $-2.16^{\dagger}$ & -4.39 & 0.08 \\
Day(6) & $(1.14)$ & & \\
& 0.26 & -1.98 & 2.49 \\
\hline
\end{tabular}

* Significant at a 0.05 level, + Significant at a 0.1 level.

regular intervals, the excitement generated from these sorts of exceptional events is expected, and therefore not unsettling. As a consequence they tend to reduce the number of subsequent suicides, since their reoccurrence is a form of stability. As a group, repeated events on average had insignificant, negative effects on excess suicides (mean $=-4.4, \mathrm{df}=76, \mathrm{p}=0.33$ ).

Extending the same study to the time series analytical framework developed earlier, we observe that constructive events are associated with a decrease in suicide in the days that immediately follow them. Table 7 reports the results from this analysis.

These results suggest that the kinds of exceptional events considered here induce solidarity in their wake, rather than anomie. That ritualistic-constructive-events are associated with solidarity is, of course, a key idea of Durkheim's. While it is not required that these events be associated with declines in the daily suicide rate for us to be convinced that anomie, not imitation, is the mechanism behind increased mortality following disruptive events such as celebrity suicides, the confirmation of an implication of a theory increases our confidence (Lieberson and Horwich 2008).

\section{Event Selection}

Two features of our event data pose a threat to the validity of the claims we have so far advanced. The first is that given the fact that any of the events in our event 


\section{Samples include $75 \%$ of Total Events}

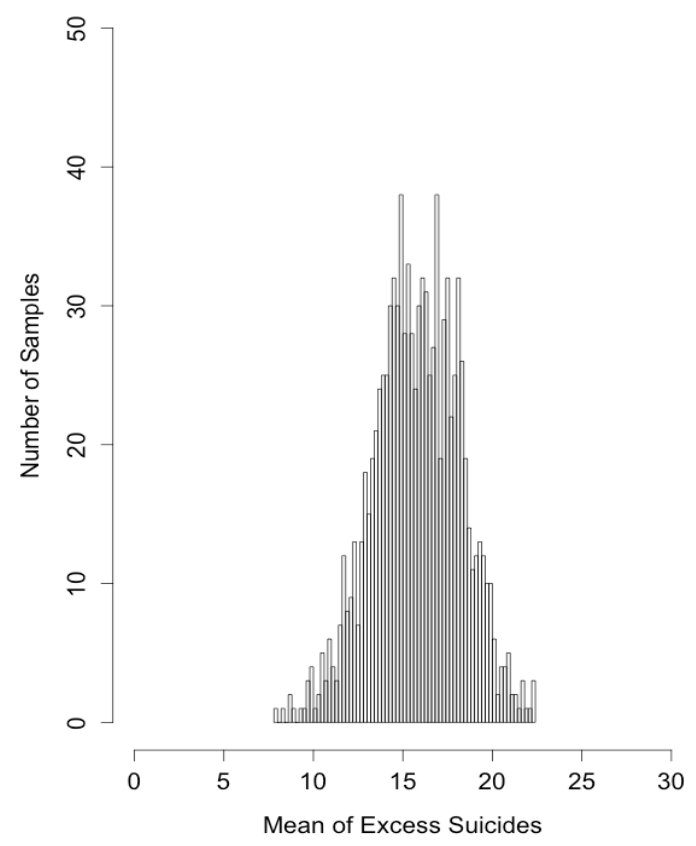

\section{Samples include $\mathbf{5 0 \%}$ of Total Events}

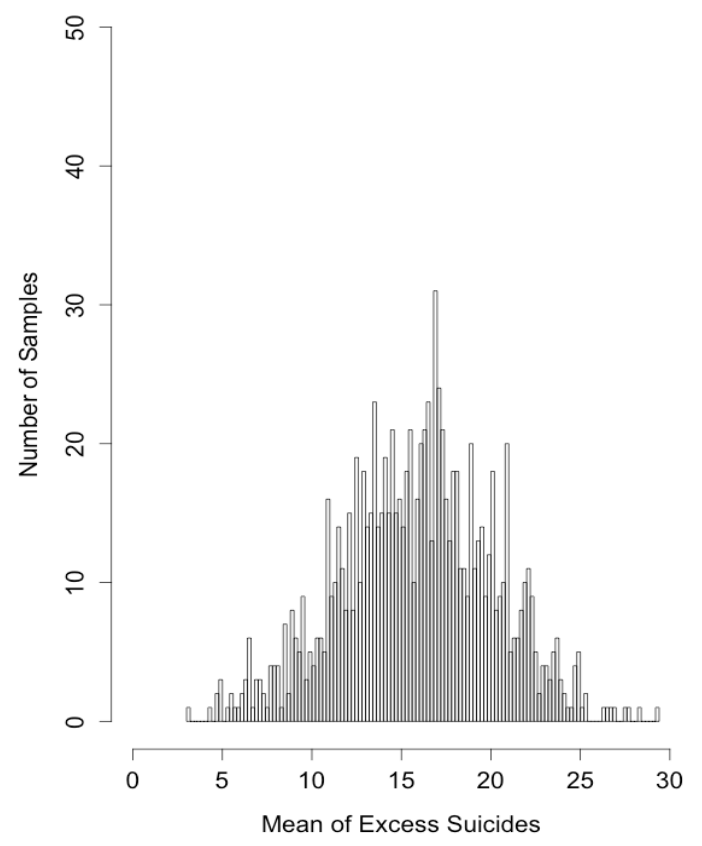

Figure 3: Robustness of effects for different samples of events

population - those that meet the screening criteria identified previously-lead to a decline in the number of suicides rather than an increase, it is possible that the results we observe here are just an accidental outcome of the specific sample of events that we use. ${ }^{9}$ In order to make sure this is not the case, and to assess the robustness of the quasi-experimental paired t-test results, we randomly select 75 percent and 50 percent of the total events in the study and then perform a twotailed paired t-test on the events selected at random. We repeat this 1000 times at each percentage level, generating a distribution of paired t-tests calculating the difference between the experimental and control group means for the various potential random groups of events given that 1-x percent of the events are excluded.

Independent of the proportion of the events selected we typically observe an excess of 15-20 suicides for the full period. The results of these analyses are reported in Figure 3, which shows histograms for excess suicides for the 1000 event samples by inclusion proportion. One can observe that deleting one quarter of all the events has absolutely no effect; 99.8 percent of the samples at the 75 percent inclusion level are significant. When we reduce the sample by half, just over 82.5 percent of the samples are significant. The stability of the outcomes for the 75 percent inclusion rate suggests that the relationship between events and excess suicide is remarkably robust.

We observed earlier that every day has an event that is featured as the lead story in the New York Times. A critic might imagine that any selection of 94 events selected 


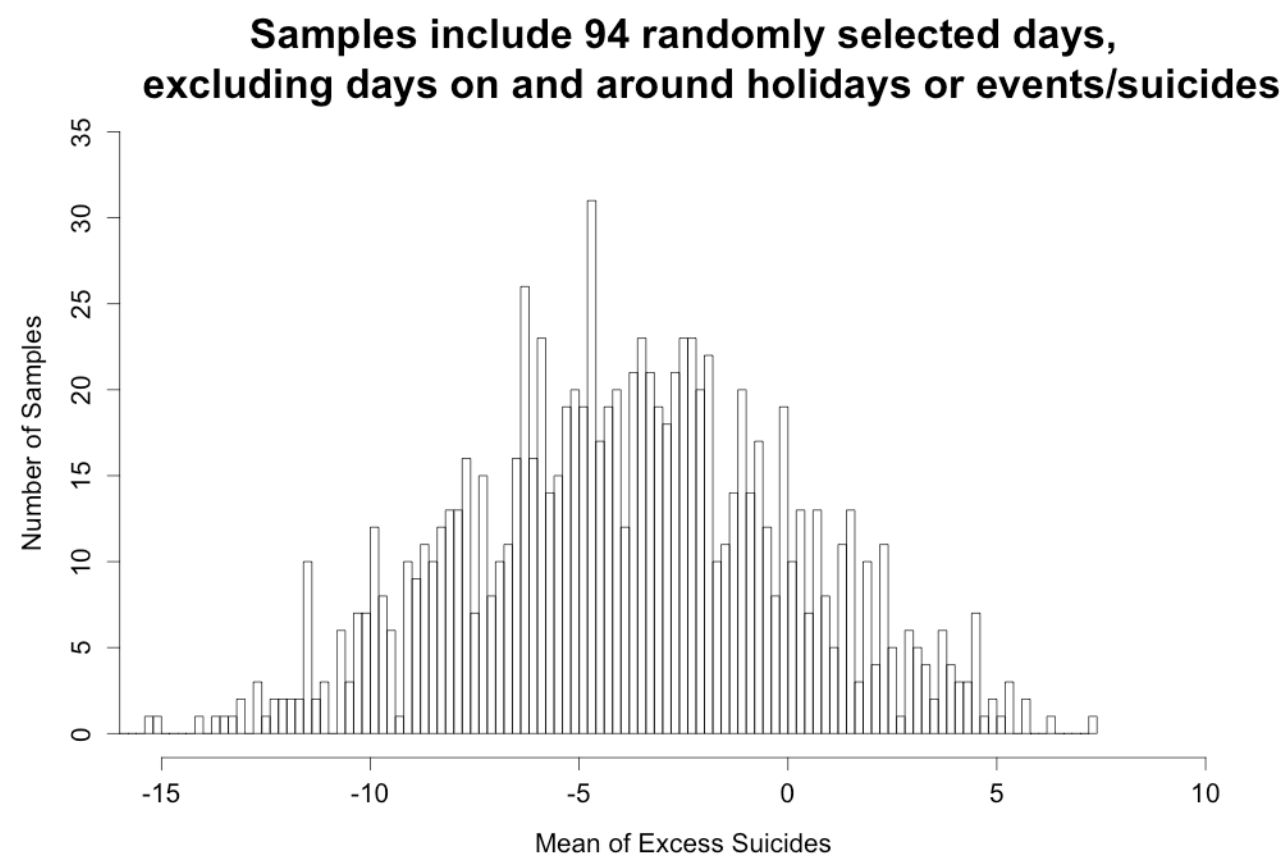

Figure 4: Robustness of effects for 1000 random samples of non-event or suicide days

at random across the entire observation window (1973-1988) could be associated with a statistically significant increase in suicide. If this were the case, then our argument that disruptive, exceptional events induce anomie and are associated with excess suicide would be falsified. To assess this possibility, we select 1,000 samples of 94 days (where each day is associated with an "event" by definition; that is, something identified as the lead story in the New York Times), excluding events that border holidays or the events and celebrity suicides already selected, and enumerate the suicides that follow their occurrence in order to ascertain if they lead to excess suicides. The results of this analysis are reported in Figure 4.

From even cursory examination of Figure 4, it is self-evident that randomly selected days-and the events associated with them-are not associated with excess suicide. Only 0.2 percent of the 1,000 samples have significantly more than zero excess suicides, which is, of course, less than what one would anticipate by chance.

The observation that exceptional events lead to excess suicide is therefore not an artifact of the specific events that we have selected. These events were exceptional, and they had an impact on suicidality. In contrast, constructive events, which happen routinely, on a schedule, do not have such an effect. Routine events of another kind - the stuff that happens every day and contributes to the news but which is not deeply salient-have no effect. This makes sense, since anomie as a state should only be induced by exceptional events. 


\section{Discussion}

When celebrities kill themselves, more often than not more people than would normally be expected to commit suicide do so within a very short period of time. Late in the nineteenth century this kind of observation appeared to provide Tarde with empirical support for his critique of Durkheim, a critique predicated on the idea that the fundamental elements of society were interactional and often based on imitation. As we all know, for the most part, not counting a few exceptions, Tarde lost the battle over what the discipline of sociology ought to look like. He even lost the battle over suicide. Aside from a few perfunctory remarks in introductory textbooks, it is Durkheim and his argument about the forms of suicide, not Tarde, that are routinely stressed as a canonical achievement for our discipline. But weirdly, though Tarde lost the war (sociology) and the battle (suicide), he won a skirmish (imitation as driving some suicides).

The Tardean victory, if one can call it that, is the product of three disciplinary bad habits. The first is the bad habit of assuming that ideas that seem obvious are obviously right. The second is a disciplinary tendency to accept the results of research strategies that are oriented towards defeating a null hypothesis as versus a serious contending hypothesis. The third bad habit is acquiescence to disciplinary inertia that orients research towards replication of the frames in which problems are first organized. Thinking of just this third leg of the stool, the moment one peeks out of the standard design frame, in this and perhaps other cases, the fragility of the whole edifice seems almost too obvious. This in any case is one of the observations arising from this article.

The second leg of the stool-assessing hypotheses about social life in competition with the null hypothesis that there is no structure-is something that we routinely suggest avoiding when advising young scholars setting out to make their mark. Here, by testing the imitation mechanism in light of a serious competing hypothesis-that events may induce anomie and are consequently associated with an increase in suicide in their immediate wake-we can observe that celebrity suicides induce excess suicides because they are anomie-inducing rather than imitation-inducing events.

In this regard, theories ought to be fecund. The imitation theory, for example, ought to carry implications for homophily with respect to celebrity suicide modality and social demographic characteristics and the modalities of suicide and characteristics of individuals whose suicide follows in their wake. While such homophily is not required by the theory-one need only consider the diffusion of fads that involve the imitative adoption of styles that cross ethnic, class, or cultural subgroup lines for obvious counterexamples-such homophily is logically entailed. One can assess how robust a mechanism is by assessing whether the logical extensions of the mechanism are in fact operative. In this sense, while the absence of homophily does not falsify the imitation hypothesis, it could hardly be said that it is a finding that is in any way supportive.

By implication, anomie as a mechanism is strongly supported by the observation that exceptional yet repetitive events are solidarity-inducing events that decrease daily suicide incidence in their wake. While the anomie mechanism does not require 
this to be the case-in the same way that the imitation theory does not require that we observe homophily - the fact that such events have an attenuating influence on suicide is supportive. Similarly, the observation that positive events have a stronger impact than negative events - which may be associated with both an increase in anomie and an increase in solidarity-is strongly supportive of anomie as the operative mechanism.

The first leg of the stool-which is that it just seems reasonable that imitation is operative-is responsible for a whole array of lay and professional thoughts on the effects of the behaviors of some on the behaviors of others. It is worth noting that routine expectations may fail when the expectation is built from experience at one level of analysis and applied at another. Though there is a strong and enduring literature on imitation effects, often cast in an influence paradigm, and though we all have the experience of being influenced by those close to us, the supports for imitation arising from events or alters significantly more distal are far weaker. Applying the logic of interpersonal interaction and the routine expectations that follow from such a logic to a broader class of relations (asymmetric and imaginary) that we have with celebrities is likely to fail us precisely because that application jumps levels of analysis. Thus the scope conditions for imitation are likely to prescribe against the kinds of arguments that motivate those whose project is to resurrect what is surely one of the weakest of the arguments Tarde advanced against Durkheim, not ironically for the same reason that Tarde's brilliant observations on interaction as the foundation for moral life fail to scale.

Of course, like all studies, this one suffers from possible limitations. The most obvious is that our data structures run out in 1988. It is possible that salient events, whether positive or negative, no longer disrupt collective life and induce anomie. Likewise it is possible that in an age of increased celebrity fascination, the effects of a celebrity suicide are amplified. But though it is possible that the proximate temporal framework matters, it seems unlikely. After all, the effect we document in this article appears to have been stable for the 100 years between the publication of Suicide in 1897 and the end of our data structure in 1988. Things change, but not without reason, and though there have been many changes in the world since 1988, the social suicide rate, with its slow secular increase, has not been one of them.

\section{Notes}

1 There is an irony here for a paper supporting Tarde over Durkheim. The title of the paper refers to Goethe's famous novel "The Sorrows of Young Werther," in which Werther commits suicide because of dissonance arising out of a love triangle (cf. Bearman and Moody 2004 for measurement of anomic social positions using intransitive triads such as Werthers'). The irony, of course, is that Werther kills himself for the "most Durkheimian of reasons." The novel apparently led young men "throughout Europe to dress in the clothing style described for Werther" (Wikipedia), although there is no evidence that it led to an increase in suicide among young men, over and above the rate that would be expected for embeddedness in an intransitive triad. 
2 The period under consideration here is 1973-1988, when it was actually expected that Congress would pass legislation, act on white house nominations for official positions, and so on.

3 It is important to remember that excess suicide would only be observed if anomie increased as a consequence of an event; some events, such as the declaration of war or the events of $9 / 11$, should lower the suicide rate because they induce greater solidarity. Cf, Durkheim, Suicide (p 208): “[G]reat social disturbances... force men to close ranks and confront the common danger, the individual thinks less of himself and more of the common cause."

4 All events with a holiday in their experimental period are excluded, as are events that follow four days or fewer after a holiday. When holidays occurred in the latter part of an event's control period, we followed Bollen and Phillips (1982) and moved the control period back one additional week.

5 Bollen and Phillips report results for 1972-1976. Our replication of their data for that period returns consistent results. However, for the 1972 data, the NCHS processed only a 50 percent sample of death records. Bollen and Phillips-to keep the suicide counts for 1972 comparable to the counts for later years-doubled the 1972 figures. Thus, for example, a publicized suicide in 1972 that was associated with 55 deaths is coded as associated with 110 excess deaths. Doubling a 50 percent sample is not the same as working with the whole population, and one can see that this might have the effect of doubling the impact of the 1972 celebrity suicides. In order to handle all of our data similarly, we restrict our analyses to data from 1973-1988. Daily suicide data are not reported after 1988, providing a temporal bound for this study.

6 Bollen and Phillips report near significance in their paper because they use a one-tailed ttest. We instead use a two-tailed paired t-test, and we analyze highly publicized suicides with a two-tailed test to aid comparability between the two types of events. This changes the significance for highly publicized suicides.

7 Bollen and Phillips do not restrict their suicides to those reported on the front page of the New York Times. Instead they select all suicides reported twice on major television news outlets. Consequently, their sample may be less "famous" than a more restrictive set of suicides that warrant New York Times coverage. This may account for the attenuated finding. We replicate their strategy here, however, to ensure our results are not an artifact of their coding decision. We eliminated all highly publicized suicides not on the front page of the New York Times and reran the analysis. Highly publicized suicides in this more restrictive sample led to 0.41 excess suicides on average $(t=0.03, \mathrm{df}=48)$, fewer than observed in the first sample. Additionally, the results from the time series analysis are less significant.

8 There are no observed differences by age, and we did not detect a spatial effect consistent with imitation.

9 While the global robustness test conducted here is a better strategy than idiosyncratic selection of seemingly weird events to delete, a number of readers wondered whether our results would obtain if we deleted the "freezing of Libyan assets." They do. Likewise, readers wondered whether the "re-election of Margaret Thatcher," although not on a schedule, was not better coded as a constructive event than a disruptive event. Deleting it from this category and adding it to the "constructive" category does not change our results. 


\section{References}

Abbott, Andrew. 2004. Methods of discovery. New York: W.W. Norton \& Co.

Baron, James N. and Peter C. Reiss. 1985. "Same Time, Next Year: Aggregate Analyses of the Mass Media and Violent Behavior." American Sociological Review 50(3):347-363. http://dx.doi.org/10.2307/2095544.

Bearman, Peter S. 1991. “The Social Structure of Suicide." Social Forum 6(3):501-524. http: //dx.doi.org/10.1007/BF01114474.

Bearman, Peter S. and James Moody. 2004. "Suicide and Friendships Among American Adolescents." American Journal of Public Health 94(1):89-95. http://dx.doi.org/10. 2105/AJPH.94.1.89.

Berkowitz, Leonard and Jacqueline Macaulay. 1971. "The Contagion of Criminal Violence." Sociometry 34(2):238-260. http://dx . doi .org/10.2307/2786414.

Bollen, Kenneth A. and David P. Phillips. 1982. “Imitative Suicides: A National Study of the Effects of Television News Stories." American Sociological Review 47(6):802-809. http://dx.doi.org/10.2307/2095217.

Bollen, Kenneth A. and David P. Phillips. 1981. "Suicidal Motor Vehicle Fatalities in Detroit: A Replication." American Journal of Sociology 87(2):404-412. http://dx.doi.org/10. $1086 / 227464$.

Cantor, Christopher H., Peter Sheehan, Phillip Alpers, and Paul Mullen. 1999. "Media and Mass Homicides." Archives of Suicide Research 5(4):283-290. http://dx . doi .org/10 . 1080/13811119908258339.

Durkheim, Emile, John A. Spaulding, and George Simpson. 1951. Suicide. New York: Free Press.

Durkheim, Emile and George Simpson. 1964. The Division of Labor in Society. New York: Free Press.

Etzersdorfer, Elmar and Gernot Sonneck. 1998. "Preventing Suicide by Influencing Massmedia Reporting. The Viennese Experience 1980-1996." Archives of Suicide Research 4(1):67-74. http://dx.doi.org/10.1080/13811119808258290.

Gould, Madelyn S. 2001. "Suicide and the Media." Annals of the New York Academy of Sciences 932(1):200-224. http://dx.doi.org/10.1111/j.1749-6632.2001.tb05807.x.

Gould, Madelyn S. and David Shaffer. 1986. "The Impact of Suicide in Television Movies." New England Journal of Medicine 315(11):690-694. http://dx.doi.org/10. 1056/NEJM198609113151107.

Hassan, Riaz. 1995. "Effects of Newspaper Stories on the Incidence of Suicide in Australia: a Research Note." Australian \& New Zealand Journal of Psychiatry 29(3):480-483. http: //dx.doi.org/10.3109/00048679509064957.

Hedström, Peter and Peter S. Bearman. 2009. The Oxford Handbook of Analytical Sociology. Oxford: Oxford University Press.

Huh, Gi Y., Gam R. Jo, Kwang H. Kim, Yong W. Ahn and Sang Y. Lee. 2009. “Imitative Suicide by Burning Charcoal in the Southeastern Region of Korea: The Influence of Mass Media Reporting." Legal Medicine 11:S563-S564. http://dx.doi .org/10.1016/j . legalmed.2009.01.099.

Jerolmack, Colin and Shamus Khan. 2014. "Talk Is Cheap: Ethnography and the Attitudinal Fallacy." Sociological Methods \& Research 43(2):178-209. http://dx.doi.org/10.1177/ 0049124114523396. 
Jonas, Klaus. 1992. "Modelling and Suicide: A Test of the Werther Effect." British Journal of Social Psychology 31(4):295-306. http: //dx . doi .org/10.1111/j . 2044-8309.1992. tb00974.x.

Kessler, Ronald C. and Horst Stipp. 1984. "The Impact of Fictional Television Suicide Stories on U.S. Fatalities: A Replication." American Journal of Sociology 90(1):151-167. http://dx.doi.org/10.1086/228051.

Kessler, Ronald C., Geraldine Downey, J. Milavsky and Horst Stipp. 1988. “Clustering of Teenage Suicides after Television News Stories about Suicides: a Reconsideration." The American Journal of Psychiatry 145(11):1379-1383. http://dx. doi .org/10.1176/ajp. 145. 11.1379.

Latour, Bruno and Vincent A. Lépinay. 2009. The Science of Passionate Interests. Chicago: Prickly Paradigm Press.

Latour, Bruno. 2010. “Tarde's Idea of Quantification." Pp. 147-164 in The Social After Gabriel Tarde: Debates and Assessments. 1st ed., edited by Matei Candea. New York: Routledge.

Legewie, Joscha. 2013. "Terrorist Events and Attitudes toward Immigrants: A Natural Experiment." American Journal of Sociology 118(5):1199-1245. http://dx.doi .org/10 . $1086 / 669605$.

Lester, David and Aaron T. Beck. 1975. "Suicide and National Holidays." Psychological Reports 36(1):36-52. http://dx.doi .org/10.2466/pr0.1975.36.1.52.

Lieberson, Stanley and Joel Horwich. 2008. "Implication Analysis: A Pragmatic Proposal for Linking Theory and Data in the Social Sciences.mpSociological Methodology 38(1):1-50. http://dx.doi.org/10.1111/j.1467-9531.2008.00199.x.

Merton, R. 1968. "The Matthew Effect in Science: The Reward and Communication Systems of Science are Considered." Science 159(3810):56-63. http://dx.doi.org/10.1126/ science.159.3810.56.

Miller, Todd Q., Linda Heath, John R. Molcan, and Bernard L. Dugoni. 1991. “Imitative Violence in the Real World: A Reanalysis of Homicide Rates Following Championship Prize Fights." Aggressive Behavior 17(3):121-134. http://dx . doi .org/10.1002/ 1098-2337 (1991) $17: 3<121$ : : AID-AB2480170302>3 . 0 . CO;2-U.

Phillips, David P. 1978. “Airplane Accident Fatalities Increase Just After Newspaper Stories About Murder and Suicide." Science 201(4357):748-750. http://dx . doi .org/10.1126/ science.201.4357.748.

Phillips, David P. 1974. "The Influence of Suggestion on Suicide: Substantive and Theoretical Implications of the Werther Effect." American Sociological Review 39(3):340-354. http: //dx.doi.org/10.2307/2094294.

Phillips, David P. 1982. "The Impact of Fictional Television Stories on U.S. Adult Fatalities: New Evidence on the Effect of the Mass Media on Violence." American Journal of Sociology 87(6):1340-1359. http://dx.doi.org/10.1086/227596.

Phillips, David P. and Lundie L. Carstensen. 1986. "Clustering of Teenage Suicides after Television News Stories about Suicide." New England Journal of Medicine 315(11):685-689. http://dx.doi.org/10.1056/NEJM198609113151106.

Phillips, David P. and John Wills 1987. "A Drop in Suicides around Major National Holidays." Suicide and Life-Threatening Behavior 17(1):1-12.

Phillips, David P. 1979. "Suicide, Motor Vehicle Fatalities, and the Mass Media: Evidence Toward a Theory of Suggestion." American Journal of Sociology 84(5):1150-1174. http: //dx.doi.org/10.1086/226904. 
Phillips, David P. 1977. "Motor Vehicle Fatalities Increase just after Publicized Suicide Stories." Science 196(4297):1464-1466. http: //dx. doi .org/10.1126/science.867044.

Phillips, David P. and Lundie, L. Carstensen. 1988. "The Effect of Suicide Stories on Various Demographic Groups, 1968-1985." Suicide and Life-Threatening Behavior 18(1):100-114.

Phillips, David P. 1983. "The Impact of Mass Media Violence on U.S. Homicides." American Sociological Review 48(4):560-568. http: //dx. doi .org/10.2307/2117722.

Shadish, William R., Thomas D. Cook, and Donald T. Campbell. 2002. Experimental and quasi-experimental designs for generalized causal inference. Boston: Houghton Mifflin.

Stack, Steven. 1987. “Celebrities and Suicide: A Taxonomy and Analysis, 1948-1983." American Sociological Review 52(3):401-412. http://dx.doi .org/10.2307/2095359.

Stack, Steven. 1987. "Publicized Executions and Homicide, 1950-1980." American Sociological Review 52(4):532-540. http://dx.doi .org/10.2307/2095298.

Stack, Steven. 1996. “The effect of the media on suicide: evidence from Japan, 1955-1985." Suicide and Life-Threatening Behavior 26(2):132-142.

Stack, Steven. 1990. "Audience receptiveness, the media, and aged suicide, 1968-1980." Journal of Aging Studies 4(2):195-209. http: //dx . doi .org/10.1016/0890-4065 (90) 90014-Y.

Stack, Steven. 2002. "Media coverage as a risk factor in suicide." Injury Prevention 8(90004):30iv-32.

Tarde, Gabriel and Terry N. Clark. 1969. Gabriel Tarde on communication and social influence. Chicago: University of Chicago Press. http://dx.doi.org/10.7208/chicago/ 9780226789798.001 .0001$.

Timmermans, Stefan. 2005. "Suicide Determination and the Professional Authority of Medical Examiners." American Sociological Review 70(2):311-333. http://dx.doi . org/10 . $1177 / 000312240507000206$.

Wasserman, Ira M. 1984. "Imitation and Suicide: A Reexamination of the Werther Effect." American Sociological Review 49(3):427-436. http: / /dx . doi . org/10.2307/2095285.

Wikipedia. 2014. "The Sorrows of Young Werther" http://en.wikipedia.org/wiki/The_ Sorrowsof_Young_Werther.

Yip, Paul S. F., K. W. Fu, Kris C. T. Yang, Brian Y.T. Ip, Cecilia L. W. Chan, Eric Y.H. Chen, Dominic T.S. Lee, Frances Y.W. Law, and Keith Hawton. 2006. "The effects of a celebrity suicide on suicide rates in Hong Kong." Journal of Affective Disorders 93(1-3): 245-252. http://dx.doi.org/10.1016/j.jad.2006.03.015.

Acknowledgements: Financial support from the Interdisciplinary Center for Theory and Empirics (INCITE) at Columbia University is gratefully acknowledged. We benefited from discussion with Alix Rule, Shamus Khan, Marissa King, Mathijs De Vann, Kinga Makovi, Christopher Muller, and Adam Reich. Bearman thanks Ken Bollen and David Phillips for the stimulating conversations about their work that led to this article.

Mark Anthony Hoffman: Department of Sociology, Columbia University.

E-mail: mh3279@columbia.edu.

Peter S. Bearman: Department of Sociology, Columbia University.

E-mail: psb17@columbia.edu. 